\title{
An improved method of communication between computerized accident and emergency departments and general practitioners
}

M. J. WILliams, P. HALEY \& J. K. GOSNOLD Department of Accident \& Emergency Medicine Hull Royal Infirmary, Anlaby Road, Hull

\section{SUMMARY}

This new system of communication sends the data on four sticky labels (Fig. 1), $\infty$ one of which can be permanently left in the patients folder without taking up ${ }_{\mathbb{D}}$ too much space. Further details can be obtained by telephoning the A\&E depart- $\frac{\pi}{0}$ ment and quoting the A\&E number on the sticky label.

\section{INTRODUCTION}

Computerized Accident and Emergency (A\&E) departments using their Korner database (Pritty \& McQuillan, 1986), produce discharge letters to the General $\stackrel{\circ}{\rightarrow}$ Practitioner (GP). Existing letters are often bulky and not readily amenable for storing in the Lloyd George folders used by most GPs.

Discussion with local GPs identified their dissatisfaction with receiving a copy of the front sheet of the casualty notes. Following introduction of a new system the opinion of 262 local GPs was canvassed by questionnaire (Fig. 2).

\section{RESULTS}

A total of $71 \%(186 / 262)$ of GPs responded to the questionnaire. Several group practices responded collectively by sending one form representing the views of all $\stackrel{N}{\sigma}$ the doctors in the practice. Only $28 \%(44 / 156)$ of respondents were satisfied with $\tilde{0}$

Correspondence: M. J. Williams, Registrar in Accident \& Emergency Medicine, Hull Royal Infirmary, Anlaby Road Hull, HU3 2JZ, U.K. 


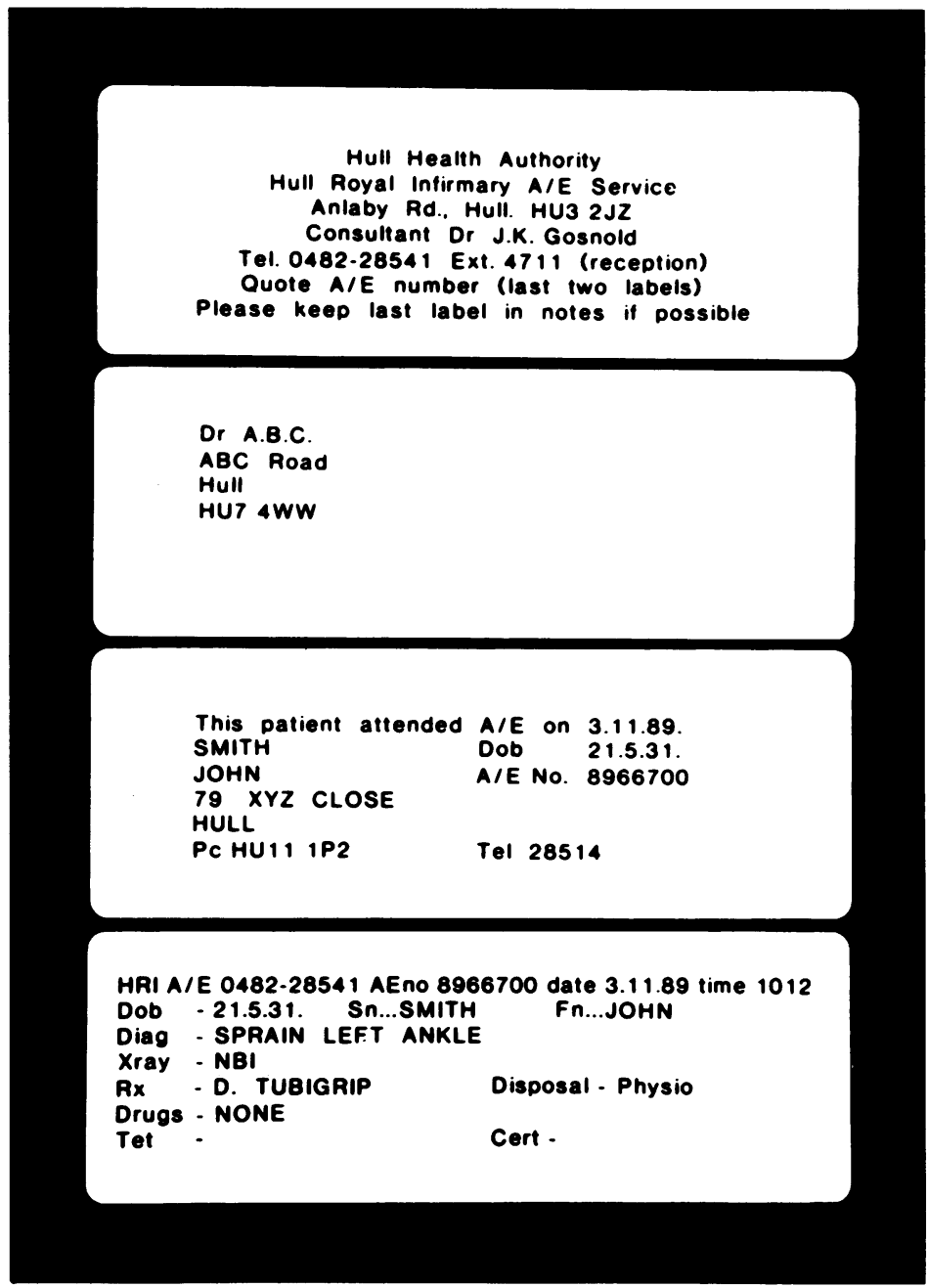

Fig. 1. Example of label.

the previous (front sheet copy) method of communication. Ninety per cent $(140 / 156)$ thought the sticky labels were preferable. In $70 \%(110 / 156)$ of cases, the communication from the A\&E department was read by a doctor in the practice, in $27 \%(42 / 156)$ of cases the practice manager or a member of the reception staff would also read the communication. In $3 \%$ of cases only the practice manager or the reception staff would read the communication. A total of $92 \%(144 / 156)$ of practices thought that the label size was satisfactory and the same number transferred the appropriate sticky label to the patients notes. A total of $76 \%(118 / 156)$ of practices thought that the labels contained enough information when correctly filled in. Eighty-one per cent $(126 / 156)$ felt that a quarterly or half yearly printout 
Please ring yes or no as appropriate

Question 1. Did you find the previous front sheet copy form of communication sent by the accident department to the practice a satisfactory system?

$$
\text { Yes }
$$

Question 2. Compared with the previous system do you find the sticky labels a better system? Yes

Question 3. Who currently reads the communications when they arrive at the practice?
a) doctor
b) practice manager
c) receptionist
d) other

Question 4. What happens to the main data label?
a) Transferred to the patients notes
b) Discarded
c) Other

Question 5. Is the current label size satisfactory

Yes

Question 6. Bearing in mind that the label gives the A\&E number of the patient which allows rapid access to the patients file by contacting the A\&E dept, do you think that enough information is contained on the main (last) label.

Yes No

Question 7. In what way do you think we can improve the information given without loosing the advantages of the compact sticky label format.

Question 8. Do you have experience of a better system than the present one:-

Question 9. In view of the current white paper proposals would a monthly printout of the patients attending the A\&E dept from your practice be helpful?

$$
\text { Yes No }
$$

Thank you very much for your help in answering this questionnaire. Please send back to the accident department using the reply paid envelope.

Fig. 2. Questionnaire distributed amongst GPS.

of patients from their practice attending the A\&E department would be useful for audit purposes.

\section{DISCUSSION}

This system which runs the locally developed PRAMS system (Patient Records and Management System) on an NCR Tower 600 computer has been in use since Maỹ 1989. The A\&E department sees approximately 78000 new patients annually. N Discharge details are obtained from the casualty notes by the reception staff and entered on computer, which in turn prints out the sticky label set for the patient. Normally the report is posted to the GP within $24 \mathrm{~h}$ of the patient attending, 
except on weekends, when delays of $48 \mathrm{~h}$ may occur. Any patient whose condition warrants a more detailed communication will also have an individual letter dictated and sent separately in addition to the sticky label printout.

It seems clear from the results of this survey that GPs are generally satisfied with the new system. However several problems were encountered. Doctors' poor handwriting was misinterpreted by reception staff, and the coding of diagnostic and treatment details by doctors was sometimes inadequate. The printer occasionally failed to align margins correctly, which is essential for printing on labels. As with other computerized discharge systems (DaCruz et al., 1989) the main criticism was that the limited format of the sticky labels restricted the amount of information dispatched.

Some GPs requested that the letters should be sent in batches; this was tried for a while but problems arose with delays in communication time because it may take several days to accumulate a significant batch of letters to an individual GP or practice. No GPs made any comments about a better computerized system although one said that he preferred a system used in the hospital 15 years previously involving a smaller casualty card and a handwritten note given to the patient to take to the GP. Another preferred a system where a communication is sent only if the patient is admitted or attends a follow up clinic.

The sticky labels sent to the GP are not currently screened by a senior member of the department. The computerized system can however be programmed to pick out any discharge diagnosis that may warrant closer scrutiny, e.g. chest pain, following which the case notes can then be reviewed.

Any department that collects the Korner data set on computer should be able to use this system with very little extra expenditure for on site tailoring by their local computer support team. Eventually when all GP practices are fully computerized the data could be transmitted directly by modem.

\section{ACKNOWLEDGMENT}

We would like to thank the medical illustrations department at the Hull Royal Infirmary for their help with the art work.

\section{REFERENCES}

Pritty P. E. \& McQuillan R. F. (1986) Computers in Accident \& Emergency Departments. British Journal Accident \& Emergency Medicine, 1(2), 37-8.

DaCruz D. J., Austin S., Richardson S. \& Bodiwla G. G. (1989) The value of computerized discharge letters. British Journal of Accident \& Emergency Medicine, 4(2), 6-9. 